\title{
Fracture toughness of concrete with basalt fiber
}

\author{
Marta Kosior-Kazberuk ${ }^{1, *}$, and Julita Krassowska ${ }^{1}$ \\ ${ }^{1}$ Bialystok University of Technology, 45E Wiejska St., Bialystok, 15-351, Poland
}

\begin{abstract}
The analysis of fracture mechanics parameters of concrete with new types of fibers is essential for the dissemination of their application and development of new methods of structural design.Fracture mechanics parameters are widely used to analyze the material behaviour and also in the design process of selected structures. The paper reports the results of an experimental programme focused on the effect of non-metallic (basalt) fibers on the fracture properties of concrete investigated in Mode I conditions. The changes in concrete properties were analysed on the basis of the critical stress intensity factor $\mathrm{K}_{\mathrm{Ic}}$, the critical value of crack tip opening displacement $\left(\mathrm{CTOD}_{\mathrm{c}}\right)$ and the fracture energy $\mathrm{G}_{\mathrm{F}}$. The addition of the basalt fibers had a slight effect on the strength properties of concrete but, at the same time, it had a significant influence on the fracture parameters by the modification of pre-cracking and particularly post-cracking behaviour of the concrete. Results of measuring the toughness and energy-absorption characteristics showed that the specimens reinforced with basalt fibers acquired a great ductile behaviour and energy absorption capacity, compared to ordinary concrete specimens.
\end{abstract}

\section{Introduction}

Fiber reinforced concrete (FRC) has been widely used in different applications in structures, such as geotechnical (dam, tunnels), road (bridges, pavements, railways objects), marine and industrial (cooling towers, floors, overlays), etc., where the major concern is toughness and first-crack strength in flexure. For engineering applications, the tension-weak nature of concrete is usually reduced by using different types of fibers. Depending on the distribution and orientation of fibers in cement matrix, the addition of fibers makes the cementitious material more isotropic and transforms it from a brittle to a quasi-brittle material. For the past 40 years the only fibers to provide the concrete with the post-cracking capacity necessary for the required structural performance have been steel. A recent development has been the introduction of various types of non-metallic fibers, which can provide similar post-cracking performance $[1,4-6,7]$.

The fracture mechanics, as one of the most significant field of science, is used to analyze the material behavior in structure $[2,12]$. The tension-softening curve may be considered as a fundamental parameter of concrete. The curve represents the post-peak load-carrying capacity of the material. The tension-softening diagram is one of the most essential properties of concrete for analyzing fracture behavior. The fracture energy is parameter of cohesive

*Corresponding author: m.kosior@pb.edu.pl 
crack models, representing cracking resistance and fracture toughness of quasi-brittle materials e.g. concrete $[10,13]$. The models are able to capture the essential features of a progressively fracturing surface and its evolution until the failure. The energy dissipation for crack propagation can be completely characterized by the cohesive stress-separation relationship [15]. The choice of descending softening function (or cohesive law) influences the prediction of the structural response and the local fracture behavior. Fracture energy has also been implemented in the mathematical models of various finite-element-programmes for non-linear modelling.

Currently, ground-supported industrial floors and pavements are major applications for fiber-reinforced concrete [6,7]. The most important requirement for concrete pavements and floors, which should be taken into account both in the design and execution process, is to avoid cracks on the surface. It is important to design and construct a suitable structure, which allows any configuration of load during service life. The approach based on the theory of fracture mechanics is used to design the large-area concrete pavement on the ground. Very often there are joint-less pavements, where the lack of anti-contraction joints is compensated by the increased content of dispersed reinforcement in the form of fibers. Dimensioning of the pavement is carried out in accordance with the procedure allowing better use of the fiber reinforced concrete properties while keeping the required total crack resistance. The groundsupported slab is assumed to work in the linear-elastic range. When calculating the ultimate stresses, the increased resistance of the concrete with fiber to cracking is taken into account, in the same way as according to theory of the kink lines, but to a limited extent, until the first cracks appear. This approach guarantees long-term and flawless use of the slab without cracks.

The use of fiber reinforced overlays (or "white topping") would appear to be a popular method for rehabilitation of both concrete and asphalt roads because of the rate of installation and the reduced thickness of material required $[6,11]$.

Applications of fracture mechanics to concrete structures can provide a rational basis for both service performance and failure analysis and can lead to a better understanding of the design methods.

Model Code 2010 [18], RILEM TC 162 [21] and ACI 544 [1] provide the guidelines to designers of structures made of concrete with fibers. However, designers hardly accept the volunteering guidelines or research results available in scientific papers. For this reason, further research on fiber reinforced concrete is still needed to confirm its advantages, particularly the flexural toughness and fracture energy which are used for design purposes. The tensile test is of limited practical value because conditions of pure tension arise rarely in real components.

In recent years, chopped basalt fibers have gained popularity among others due to their very good mechanical properties and environmentally friendly manufacturing process. The development of basalt fiber technology is due to the need for materials resistant to high temperatures, non-flammable, non-corrosive, lightweight, and characterized by significant tensile strength [23]. Initially, basalt fibers were used as insulating material. This material proved to be an excellent substitute for asbestos fiber products in terms of insulation parameters and, at the same time, a material without carcinogenic properties. For these reasons, numerous research centres in the world are involved in the study of basalt as well as chopped and continuous basalt fibers, seeking new technologies for their production and use in the building industry.

Basalt fibers are obtained from basalt rocks through melting and drawing process. Basalt ore are formed by the rock magma. During the rock magma forming process, associated with high temperature, high pressure and ambient pressure drop, the basalt ore is formed, which has extremely high chemical and thermal stability $[14,26]$. Therefore, the basalt fiber has inherited the basalt ore structure and performance characteristics, such as outstanding thermal 
stability, anti-corrosive performance, ideal heat insulation, sound absorption, and low moisture absorption. In addition, this fiber exhibits high strength and high module performance. The basalt fibers do not need any other additives, which make additional advantage in cost [25]. According to Sim et al. [23] the basalt fibers have better tensile strength than the E-glass fibers, greater failure strain than carbon fibers as well as good resistance to chemical attack, impact load and fire. These features, combined with lower cost, could make basalt fibers a suitable replacement for steel, glass, and carbon fibers in many applications [3].

However, previous studies on the use of basalt fibers in concrete are limited. Sim et al. [23] investigated the properties of concrete containing continuous basalt fiber. The results show the improvement in thermal and mechanical properties of concrete. Limited research has studied the effect of short basalt fiber on mechanical properties of geopolymeric concrete $[8,17]$. Kabay [14] reported that the addition of short basalt fibers resulted in decrease in compressive strength and at the same time the enhancement of fracture energy and reduction of abrasive wear of concrete. Branston et al. [4] have determined that the fiber geometry (length and diameter) have a significant effect on the performance characteristics of concrete element under loading both in the pre-cracking and post-cracking range. However, the full potential of fiber reinforced concrete is still not fully exploited in practice $[1,16]$.

Considering the applicability of basalt fibers further experimental studies should be conducted on the use of them in cement based composites to characterize its effects on physical and mechanical properties. Therefore, the aim of the study was to evaluate the effect of basalt fibers content on the toughness and post-cracking behavior of concrete. The fracture characteristics for concretes with basalt fibers, such as critical stress intensity factor $\mathrm{K}_{\mathrm{Ic}}$, crack tip opening displacement $\mathrm{CTOD}_{\mathrm{c}}$ and fracture energy $\mathrm{G}_{\mathrm{F}}$ were assessed using beams with initial notches in three-point-bending test.

\section{Experimental procedures}

\subsection{Characteristics of the materials and specimens}

Concrete mixtures were made with two cement types CEM I 42.5 R and CEM II/A-V 42.5 R (usually used in concrete pavements). The cement content in all mixtures tested was 320 $\mathrm{kg} / \mathrm{m}^{3}$. The water to cement ratio was equal to 0.40 and 0.50 . As an aggregate, the mixture of sand (fraction 0-2 $\mathrm{mm}$ ) and a natural aggregate with a maximum diameter of up to $16 \mathrm{~mm}$ was used. The basalt fibers with a diameter of $0.02 \mathrm{~mm}$ and a length of $50 \mathrm{~mm}$ were characterized by tensile strength of $1680 \mathrm{MPa}$, elastic modulus of $89 \mathrm{GPa}$ and density of 2600 $\mathrm{kg} / \mathrm{m}^{3}$.

The basalt fibers were added to concrete at three contents $\left(\mathrm{V}_{\mathrm{f}}\right)$ of $2.0,4.0$ and $8.0 \mathrm{~kg} / \mathrm{m}^{3}$, which gave volume fractions $0.075 \% ; 0.15 \%$ and $0.31 \%$, respectively. The fibers were added as a replacement of part of coarse aggregate by volume. Comparatively, the properties of concretes with no added fiber were also tested.

The polycarboxylate polymer based super-plasticizer was used to minimize fiber clumping and enhance fiber dispersion in concrete mix. The super-plasticizer was applied in the amount of $1.0 \%$ of cement mass. The dry aggregate was mixed with fibers followed by cement. The materials were dry mixed for 2 min before adding the water with superplasticizer. Mixing continued for further $4 \mathrm{~min}$. The time of mixing was considered sufficient for the proper dispersion of fibers in the mix without causing a "balling" effect. The specimens were vibrated in moulds and then stored under polyethylene cover for 24 hours.

For each fiber-dosage combination the notched beams of size $100 \times 100 \times 400 \mathrm{~mm}$ were prepared for fracture parameters determination. Every series was composed of four 
replicates. Moreover, the beams $(100 \times 100 \times 400 \mathrm{~mm})$ for flexural strength were also cast and cubes $(100 \times 100 \times 100 \mathrm{~mm})$ for the compressive strength test were cut from them. After demoulding all specimens were cured in water at the temperature of $18 \pm 2^{\circ} \mathrm{C}$ till they were tested.

\subsection{Test procedures}

The flexural strength of concrete was defined by the load capacity at the first crack. The compressive strength was determined according to EN 12390-3 [9] using cubes of size 100 $\mathrm{mm}$.

The fracture performance of concretes with fibers and control concrete without reinforcement was tested in accordance with the recommendations of RILEM Fracture Mechanics Committee [19, 20]. The notched beams of size $100 \times 100 \times 400 \mathrm{~mm}$ were used for three-point bending test corresponding to Mode I conditions. The initial saw-cut notch with a depth equal to $30 \mathrm{~mm}$ and width of $3 \mathrm{~mm}$ was located in the mid-span place. The geometry of specimen and the way of load were presented in Fig. 1 . The elongated U-notches $\left(\mathrm{a}_{0} / \mathrm{d}=\right.$ 0.30 ) were sawn under wet conditions one day before the test. Each series was composed of 4 replicates.

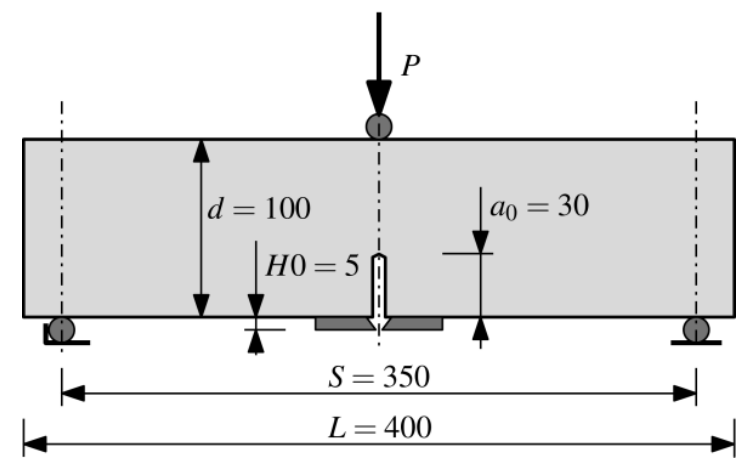

Fig. 1. Fracture testing configuration and geometry of notched specimen.

The universal testing machine (MTS 322) with closed-loop servo control was used to achieve a stable failure of specimens. The load-deflection $(\mathrm{P}-\delta)$ curves and load - crack mouth opening displacement (P-CMOD) curves were determined for the fracture process analysis.

The clip gauge was used to measure the CMOD values. The length of gauge was chosen in such a way that possible errors caused by the bending effects were avoided. The rate of loading was controlled by the constant rate of increment of crack mouth opening displacement. The applied load was automatically reduced (unloading phase) when the load passed the maximum value and was about $95 \%$ of the peak load. When the applied load was reduced to ca. $100 \mathrm{~N}$, reloading was applied. The cycles of loading and unloading were repeated four times, and then the specimen was loaded up to failure.

The fracture parameters considered were the critical stress intensity factor $\mathrm{K}_{\mathrm{Ic}}$ and the critical tip opening displacement $\mathrm{CTOD}_{\mathrm{c}}$. The critical stress intensity factor $\mathrm{K}_{\mathrm{Ic}}$ is defined as the stress intensity factor calculated at the critical effective crack tip, using the measured maximum load. The critical crack tip opening displacement $\mathrm{CTOD}_{\mathrm{c}}$ is defined as the crack tip opening displacement calculated at the original notch tip of the specimen, using the measured maximum load and the critical effective crack length $\mathrm{a}_{\mathrm{c}}$. A crack of given length ( $\mathrm{a}_{0}=30 \mathrm{~mm}$ in current analysis) critically propagate when it reaches the length of $\mathrm{a}_{\mathrm{c}}$. The values of $\mathrm{K}_{\mathrm{Ic}}$ and $\mathrm{CTOD}_{\mathrm{c}}$ were determined using procedure and equations given in RILEM 
TC 89-FMT Recommendation [20], based on the fracture model (TPFM) elaborated by Jenq and Shah [12], assuming cyclic loading-unloading test procedure. Both parameters are related to the critical stress $\sigma_{\mathrm{c}}$ initiating the crack propagation and the effective length of the critical crack $a_{c}$. The assessments for LEFM application by Jenq and Shah were described in details in [22].

The fracture energy $\left(\mathrm{G}_{\mathrm{F}}\right)$ is defined as the area under the load-deflection curve per unit fractured surface area. The fracture energy of concretes tested in this experimental study, was evaluated using the procedure given by RILEM TC 50-FMT Recommendation [19], in which energy was calculated from load-deflection curves obtained by performing a three-point bending test,dividing by the area of ligament, which is defined as the projection of the fracture zone on a plane perpendicular to the beam axis. The scatter of the calculated values of $\mathrm{G}_{\mathrm{F}}$ results from the inevitable random length of the tail region of $\mathrm{P}-\delta$ curve and also from the uncertainty in extrapolating the curve descent to zero. To reduce the impact of factors mentioned on the scatter of $\mathrm{G}_{\mathrm{F}}$ the plot was cut down when the load was approximately equal to $0.05 \mathrm{P}_{\max }(100 \div 200 \mathrm{~N})$. The area of the cross section of specimen, to which the total energy value was referred, was determined based on the width of the test specimen $b$ and the depth $\mathrm{d}$ excluding the notch $\left(\mathrm{a}_{0}=30 \mathrm{~mm}\right)$.

The P- $\delta$ diagram for calculation of total value of fracture energy $G_{F}$ and plastic $G_{F p l}$ and elastic $\mathrm{G}_{\mathrm{Fel}}$ parts of energy absorbed until crack propagation [24] was presented in Fig. 2.

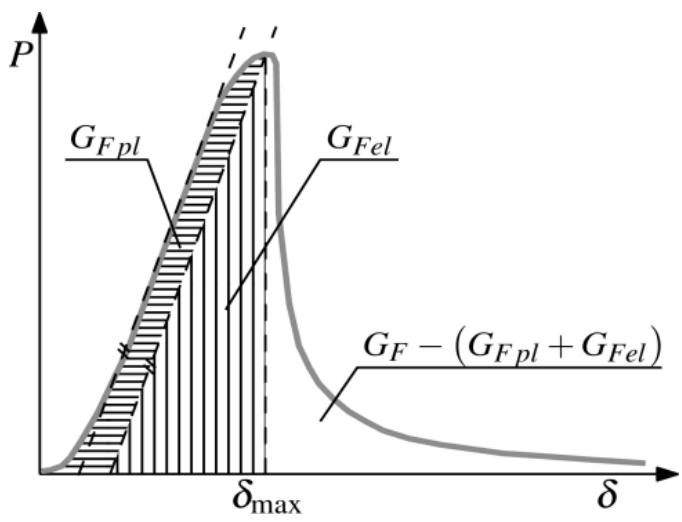

Fig. 2. Load $\mathrm{P}$ versus deflection $\delta$ diagram for fracture energy calculation.

\section{Analysis of test results}

The test results of strength properties, determined after 28 days of curing, characterizing the concretes tested, were presented in Table 1. The increase in basalt fiber content caused slight increase in compressive strength and significant increase in flexural strength of concretes tested. The strength parameters were also determined by the type of cement used and the w/c ratio. Generally, better performances were obtained for concretes containing CEM I 42.5 R cement then CEM II/A-V 42.5 R.

The fracture toughness $\left(\mathrm{K}_{\mathrm{Ic}}\right)$ and the critical crack tip opening displacement $\left(\mathrm{CTOD}_{\mathrm{c}}\right)$ were determined on the basis of load $\mathrm{P}$ vs. CMOD curves obtained for the concrete specimens subjected to cyclic loading-unloading.

Table 1. Measured average values of concretes with various content of fiber $V_{f}$ : compressive strength $\mathrm{f}_{\mathrm{cm}}$ and flexural strength $\mathrm{f}_{\mathrm{ctm}}$. 


\begin{tabular}{|c|c|c|c|c|}
\hline Cement & $\mathrm{w} / \mathrm{c}$ & $\begin{array}{l}V_{f} \\
\left(\mathrm{~kg} / \mathrm{m}^{3}\right)\end{array}$ & $\begin{array}{l}f_{c m} \\
(\mathrm{MPa})\end{array}$ & $\begin{array}{l}\mathrm{f}_{\mathrm{ctm}} \\
(\mathrm{MPa})\end{array}$ \\
\hline \multirow{8}{*}{$\begin{array}{l}\text { CEM I } \\
42.5 \mathrm{R}\end{array}$} & \multirow[t]{4}{*}{0.40} & 0.0 & 67.54 & 4.51 \\
\hline & & 2.0 & 65.73 & 5.48 \\
\hline & & 4.0 & 72.77 & 4.89 \\
\hline & & 8.0 & 75.63 & 5.62 \\
\hline & \multirow[t]{4}{*}{0.50} & 0.0 & 65.17 & 4.14 \\
\hline & & 2.0 & 66.26 & 4.18 \\
\hline & & 4.0 & 70.67 & 5.00 \\
\hline & & 8.0 & 72.50 & 5.28 \\
\hline \multirow{8}{*}{$\begin{array}{l}\text { CEM II/A-V } \\
42.5 \mathrm{R}\end{array}$} & \multirow[t]{4}{*}{0.40} & 0.0 & 52.28 & 5.03 \\
\hline & & 2.0 & 55.78 & 5.10 \\
\hline & & 4.0 & 58.26 & 5.64 \\
\hline & & 8.0 & 60.19 & 5.89 \\
\hline & \multirow[t]{4}{*}{0.50} & 0.0 & 51.09 & 4.84 \\
\hline & & 2.0 & 54.52 & 4.65 \\
\hline & & 4.0 & \begin{tabular}{|l|}
54.87 \\
\end{tabular} & 4.89 \\
\hline & & 8.0 & 58.88 & 5.55 \\
\hline
\end{tabular}

The initial parts of characteristic P-CMOD plots obtained for concretes with w/c $=0,40$ made of CEM I 42.5 cement are shown in Fig. 3 and for concretes made of CEM II/AV 42.5 R cement - in Fig. 4.

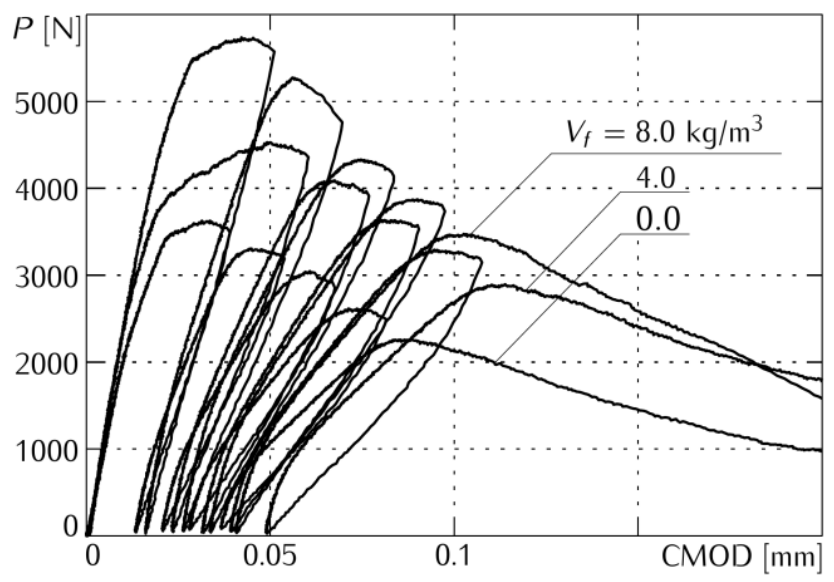

Fig. 3. Load P-CMOD plots for concretes with w/c $=0.40$ (CEM I 42,5 R) with different content of basalt fibers $\mathrm{V}_{\mathrm{f}}$.

The analysis of the P-CMOD plots (Figs 3 and 4) showed that as the fiber content increased, the length of the linear segment of the first phase of graph (elastic phase) increased. After the linear segment of P-CMOD curve, deviation from a linear response was observed and the load reached the maximum value, which indicated the onset of the crack initiation at the tip of the notch. Increasing fiber content caused the increase in the value of critical load. In the stable pre-cracking phase, the $\mathrm{P}-\mathrm{CMOD}$ relationship was nonlinear. When the maximum value of load was reached, the unstable crack development occurred. In the postcracking range, the material softening and the gradual decrease in the load were observed with the increase of crack mouth opening. 


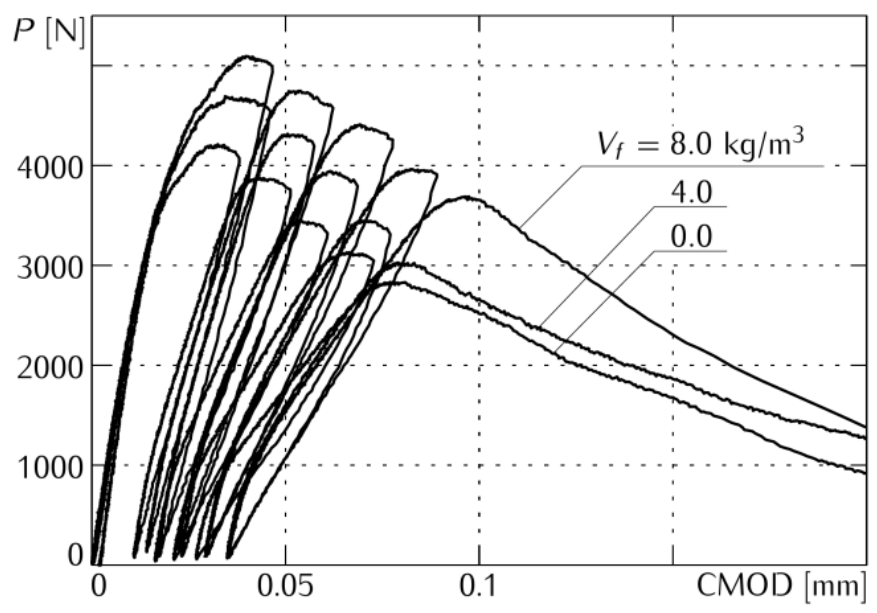

Fig. 4. Load P-CMOD plots for concretes with w/c $=0.40($ CEM II/A-V 42,5 R) with different content of basalt fibers $\mathrm{V}_{\mathrm{f}}$.

The results of the critical stress intensity factor $\left(\mathrm{K}_{\mathrm{Ic}}\right)$ and the critical value of crack tip opening displacement CTODc, derived from the $\mathrm{P}-\mathrm{CMOD}$ relationships for different fiber content, were shown in Figures 5 and 6, respectively. Comparing the mean values against the scattering the measurement results, it was found that the fiber content, type of cement and w/c ratio had significant influence on the values of both parameters.

The increase in fiber content resulted in a significant increase in $\mathrm{K}_{\mathrm{Ic}}$, which means an increase in fracture toughness. The greatest changes due to the incorporation of fibers were observed for concrete with CEM I cement. In comparison to control concrete without fiber, the composites of w/c ratio equal to 0.40 and 0.50 , containing $4.0 \mathrm{~kg} / \mathrm{m}^{3}$ of fiber, achieved $\mathrm{K}_{\mathrm{Ic}}$ values $26 \%$ and $38 \%$ greater, respectively. Further increasing the additive content to 8.0 $\mathrm{kg} / \mathrm{m}^{3}$ resulted in a $\mathrm{K}_{\mathrm{Ic}}$ value increase not exceeding $10 \%$. For concrete with w/c $=0.40$ and 0.50 made of CEM II cement, the addition of $4.0 \mathrm{~kg} / \mathrm{m}^{3}$ increased the critical stress intensive factor value by $25 \%$ and $15 \%$, respectively.

It was found that increasing the fiber content up to $4.0 \mathrm{~kg} / \mathrm{m}^{3}$ resulted in an increase in $\mathrm{CTOD}_{\mathrm{c}}$. Greater differences in $\mathrm{CTOD}_{\mathrm{c}}$ values associated with basalt fiber reinforcement were observed for CEM I cement concretes.

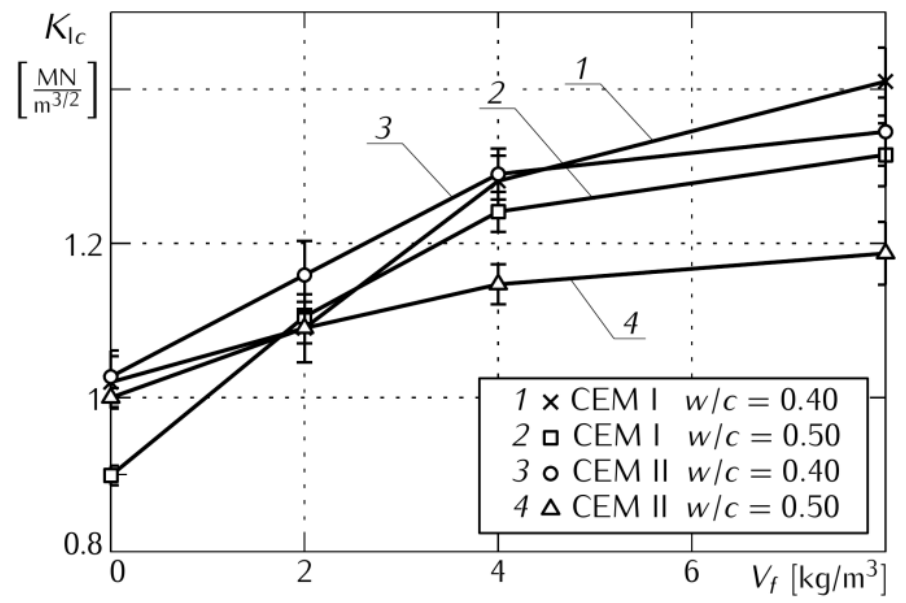

Fig. 5. Effect of fiber volume fraction $\mathrm{V}_{\mathrm{f}}(\%)$, cement type and w/c ratio on fracture toughness $\mathrm{K}_{\text {Ic. }}$ 


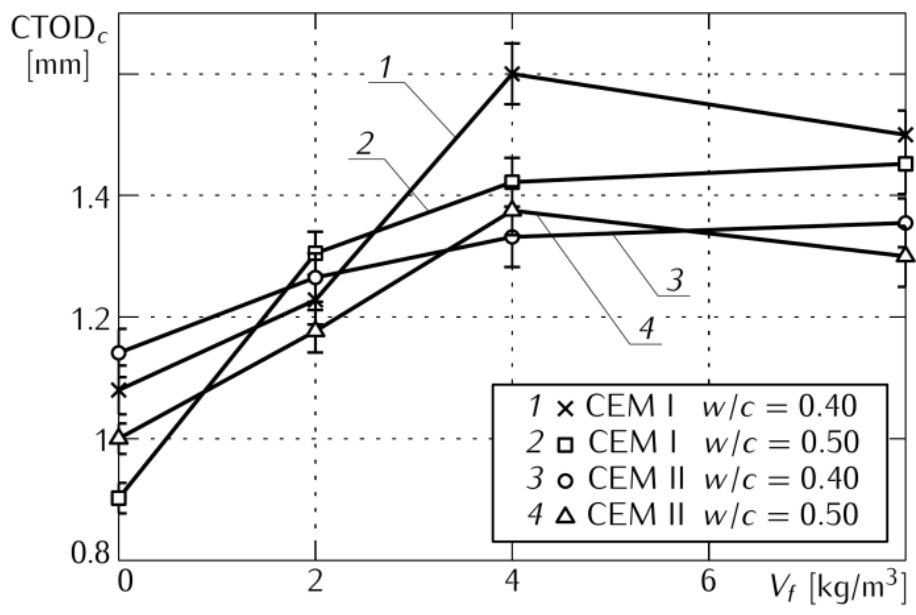

Fig. 6. Effect of fiber volume fraction $\mathrm{V}_{\mathrm{f}}(\%)$, cement type and w/c ratio on $\mathrm{CTOD}_{\mathrm{c}}$.

Until the crack is initiated, the load is transferred between the fibers and cement matrix by the adhesion forces and both the fibers and matrix are in an elastic state. As the load increases continuously, some of the microcracks may continue to develop until the deformation of the cement matrix reaches the limit value. Hence, P-CMOD plots show nonlinearity. Basalt fibers stretch across the micro-cracks performing a bridging effect by transferring stress and the test element is in a state of relative equilibrium. With further loading, the basalt fibers may break or be drawn from the cement matrix.

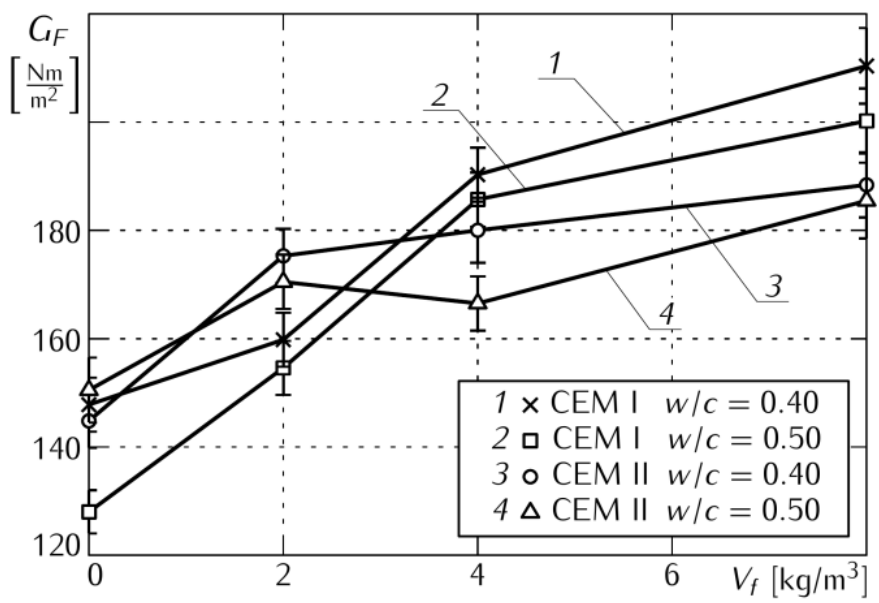

Fig. 7. Effect of fiber volume fraction $V_{f}(\%)$, cement type and w/c ratio on fracture energy $G_{F}$.

Fracture energy is characterizing the process of cracking and post-cracking strain softening of material after reaching the maximum stress. The dependence of fracture energy $\mathrm{G}_{\mathrm{F}}$ on the fiber volume fraction, cement type and w/c ratio was shown in Fig. 7. Growing fiber content has an increasing effect on the energy absorption. However, the significant effect of basalt fiber addition was observed for CEM I cement concretes. For CEM II cement concretes the increase in fiber content to 4,0 or to $8,0 \mathrm{~kg} / \mathrm{m}^{3}$ has very little influence on fracture energy. Probably, CEM I cement matrix is characterized by better adhesion to basalt fibers.

The incorporation of the basalt fiber does influence not only the post-peak behavior of concrete beam but also the pre-peak part of both load-CMODand load-deflection curves. The 
values of fracture energy given in Table 2 were calculated according to load-deflection diagrams containing both, the plastic and elastic part of the fracture energy up to the breaking load (according to Fig. 2). To give an idea about the proportion of the elastic part of the fracture energy, Table 2 illustrates elastic $G_{F e l}$ and plastic $G_{F p l}$ part of energy until crack propagation related to the total measured energy $G_{F}$. The energy demand necessary for crack initiation increased with the increase in fiber volume fraction. It may be concluded that both elastic and plastic portions of energy increased. For comparison, the values of total fracture energy were aslo given.

Table 2. Elastic $\mathrm{G}_{\mathrm{Fel}}$ and plastic $\mathrm{G}_{\mathrm{Fpl}}$ part of the fracture energy until crack propagation, $\mathrm{G}_{\mathrm{F}}-$ total fracture energy.

\begin{tabular}{|c|c|c|c|c|c|}
\hline Cement & $\mathrm{w} / \mathrm{c}$ & $\begin{array}{c}\mathrm{V}_{\mathrm{f}} \\
\left(\mathrm{kg} / \mathrm{m}^{3}\right)\end{array}$ & $\begin{array}{c}\mathrm{G}_{\mathrm{F}} \\
\left(\mathrm{Nm} / \mathrm{m}^{2}\right)\end{array}$ & $\begin{array}{c}\mathrm{G}_{\mathrm{Fpl}} \\
\left(\mathrm{Nm} / \mathrm{m}^{2}\right)\end{array}$ & $\begin{array}{c}\mathrm{G}_{\mathrm{Fel}} \\
\left(\mathrm{Nm} / \mathrm{m}^{2}\right)\end{array}$ \\
\hline \multirow{8}{*}{$\begin{array}{l}\text { CEM I } \\
42.5 \mathrm{R}\end{array}$} & \multirow[t]{4}{*}{0.40} & 0.0 & 147.8 & 9.0 & 52.0 \\
\hline & & 2.0 & 159.8 & 16.0 & 53.0 \\
\hline & & 4.0 & 190.3 & 27.0 & 78.0 \\
\hline & & 8.0 & 210.4 & 33.6 & 88.0 \\
\hline & \multirow[t]{4}{*}{0.50} & 0.0 & 128.0 & 7.0 & 39.0 \\
\hline & & 2.0 & 154.6 & 15.0 & 54.0 \\
\hline & & 4.0 & 185.7 & 24.0 & 71.0 \\
\hline & & 8.0 & 200.2 & 30.0 & 84.0 \\
\hline \multirow{8}{*}{$\begin{array}{c}\text { CEM II/A-V } \\
42.5 \mathrm{R}\end{array}$} & \multirow[t]{4}{*}{0.40} & 0.0 & 144.8 & 7.2 & 49.0 \\
\hline & & 2.0 & 175.3 & 16.0 & 54.0 \\
\hline & & 4.0 & 180.0 & 23.0 & 72.0 \\
\hline & & 8.0 & 188.4 & 28.0 & $\begin{array}{l}77.0 \\
\end{array}$ \\
\hline & \multirow[t]{4}{*}{0.50} & 0.0 & 150.5 & 10.0 & 49.5 \\
\hline & & 2.0 & 170.5 & 14.0 & 54.5 \\
\hline & & 4.0 & 166.5 & 20.0 & 59.5 \\
\hline & & 8.0 & 185.5 & 21.0 & 70.0 \\
\hline
\end{tabular}

\section{Conclusions}

The results of measuring the toughness and the energy-absorption characteristics showed that basalt fiber reinforced concrete specimens acquire a great ductile behavior and energy absorption capacity, compared to ordinary concrete specimens. The addition of basalt fiber in the tested amount of $2-8 \mathrm{~kg} / \mathrm{m}^{3}$ has a significant influence on the fracture mechanics parameters of concrete, with relatively little impact on the compressive strength of concrete. The presence of fibers has improved the fracture mechanics parameters such as $K_{I c}, \mathrm{CTOD}_{c}$, $G_{F}$ and recorded maximum values of load. The analysis of the $P$-CMOD relationships show that dispersed reinforcement can significantly change the nature of the behavior of concrete element subjected to bending in both pre-cracking and post-cracking phases. The changes in fracture mechanics parameters and the modification of $P$-CMOD plots, recorded under load, indicate that basalt fibers can increase concrete resistance to initiation and propagation of cracks. The fracture parameters of concretes with basalt fibers are also determined by type of cement. The results obtained may be useful in thedevelopment of practical applications of basalt fibers in concrete structures.

\section{Anknowlegement}

This research work was financially supported by National Centre for Research and Development, Poland; project number PBS3/A2/20/2015 (ID 245084). 


\section{References}

1. ACI 544. IR-96. State-of-the-art report on fibre reinforced concrete. Manual of concrete practice (Farmington Hills, 1998)

2. Z.P. Bažant, Fracture Mechanics 69, 165-205 (2002)

3. T.M. Borhan, Materials and Design 42, 265-271 (2012)

4. J. Branston, S. Das, S.Y. Kenno, C. Taylor, Construction and Building Materials 124, 878-886 (2016)

5. N. Buratti, C. Mazzotti, M. Savoia, Construction and Building Materials 25, $2713-2722(2011)$

6. J.L. Clarke, Design guidance for fibre-reinforced concrete (IHS BRE Press, University of Dundee, 2008)

7. Concrete Society Technical Report No 34, Concrete Industrial Ground Floors - A guide to their Design and Construction, Ed. 3 (2003)

8. D. Dias, C. Thaumaturgo, Cement \& Concrete Composites 27 (1), 49-54 (2005)

9. EN 12390-3. Testing Hardened Concrete: Compressive strength of test specimens (2011)

10. X.-H. Guo, F. Tin-Loi, H. Li, Cement and Concrete Research 29, 1055 - 1059 (1999)

11. C. High, H.M. Seliem, A. El-Safty, S.H. Rizkalla, Construction and Building Materials 96, 37-46 (2015)

12. Y.S. Jenq, S.P. Shah, Journal of Engineering Mechanics 111, 1227-1241 (1985)

13. B.L. Karihaloo, Failure of concrete, Elsevier Pergamon, 477 - 548 (2003)

14. N. Kabay, Construction and Building Materials 50, 95-101 (2014)

15. M. Kosior-Kazberuk, Materials Science (Medziagotyra) 22(4), 542-547 (2016)

16. M. Kosior-Kazberuk, J. Krassowska, Proc. of the 6th International Conference on Mechanics and Materials in Design M2D2015, 673-682 (2015)

17. W. Li, J. Xu, Material Science Engineering 505 (1-2), 178-186 (2009)

18. Model Code 2010, Comité Euro-International du Béton fib (CEB-FIP) (2012)

19. Recommendation TC 50-FMT RILEM, Materials and Structures 18, 285-290 (1985)

20. Recommendation TC 89-FMT RILEM, Materials and Structures 23, 457-460(1990)

21. RILEM TC 162-TDF, Materials and Structures 36, 560-567 (2003)

22. S.P. Shah, S.E. Swartz, Ch. Ouyang, Fracture mechanics of concrete: Applications of fracture mechanics to concrete, rock and other quasi-brittle materials (John Wiley \& Sons, New York, 1995)

23. J. Sim, C. Park, D. Moon, Composites Part B: Engineering 36, 504-512(2005)

24. K. Voit, J. Kirnbauer, International Journal of Fracture 188, 147- 157 (2014)

25. B. Wei, H. Cao, S. Song, Materials Science and Engineering 527, 4708-4715 (2010)

26. B. Wei, H. Cao, S. Song, Composites: Part A 42, 22-29 (2011) 